\title{
Impact of Plate Size on Peak Cladding Strain
}

GTRI - Reactor Conversion Program

WBS 21.2.96.2.7 - Out-of-Pile Testing and Codes

Task 13.5.1, Deliverable 2

Nuclear Engineering Division 


\begin{abstract}
About Argonne National Laboratory
Argonne is a U.S. Department of Energy laboratory managed by UChicago Argonne, LLC under contract DE-AC02-06CH11357. The Laboratory's main facility is outside Chicago, at 9700 South Cass Avenue, Argonne, Illinois 60439. For information about Argonne and its pioneering science and technology programs, see www.anl.gov.
\end{abstract}

\title{
Availability of This Report
}

This report is available, at no cost, at http://www.osti.gov/bridge. It is also available on paper to the U.S. Department of Energy and its contractors, for a processing fee, from:

U.S. Department of Energy

Office of Scientific and Technical Information

P.O. Box 62

Oak Ridge, TN 37831-0062

phone (865) 576-8401

fax (865) 576-5728

reports@adonis.osti.gov

\section{Disclaimer}

This report was prepared as an account of work sponsored by an agency of the United States Government. Neither the United States Government nor any agency thereof, nor UChicago Argonne, LLC, nor any of their employees or officers, makes any warranty, express or implied, or assumes any legal liability or responsibility for the accuracy, completeness, or usefulness of any information, apparatus, product, or process disclosed, or represents that its use would not infringe privately owned rights. Reference herein to any specific commercial product, process, or service by trade name, trademark, manufacturer, or otherwise, does not necessarily constitute or imply its endorsement, recommendation, or favoring by the United States Government or any agency thereof. The views and opinions of document authors expressed herein do not necessarily state or reflect those of the United States Government or any agency thereof, Argonne National Laboratory, or UChicago Argonne, LLC. 


\section{Impact of Plate Size on Peak Cladding Strain}

\section{GTRI - Reactor Conversion Program}

WBS 21.2.96.2.7 - Out-of-Pile Testing and Codes

Task 13.5.1, Deliverable 2

prepared by

Walid M.F. Mohamed

Nuclear Engineering Division, Argonne National Laboratory

July, 2013

This work is sponsored by the U.S. Department of Energy, National Nuclear Security Administration Office of Global Threat Reduction (NA-21) 


\section{Impact of Plate Size on Peak Cladding Strain}

Case Study: A typical monolithic plate will be simulated with different cladding thickness surrounding the "meat" which remain the same at all cases. The nominal case is a symmetric plate with plate size of L1P754 in experiment RERTR-12. Total of three cases in addition to the nominal case were simulated. One case with cladding thickness of 1.4 times that of the nominal case (thicker cladding) and another two cases with cladding thickness of 0.85 and 0.75 times the nominal case (thinner and thinnest cladding).

Model: a 2-D model of L1P754 monolithic plate.

Due to symmetry, the cladding strain will be estimated as following:

- One path will be defined at the top clad surface

- $\quad$ The cladding displacement at the top face will be determined (UT)

- $\quad$ The strain is then defined as $=U /$ one-half of plate thickness

- Maximum strain will be determined.

Cases: The following four cases are simulated

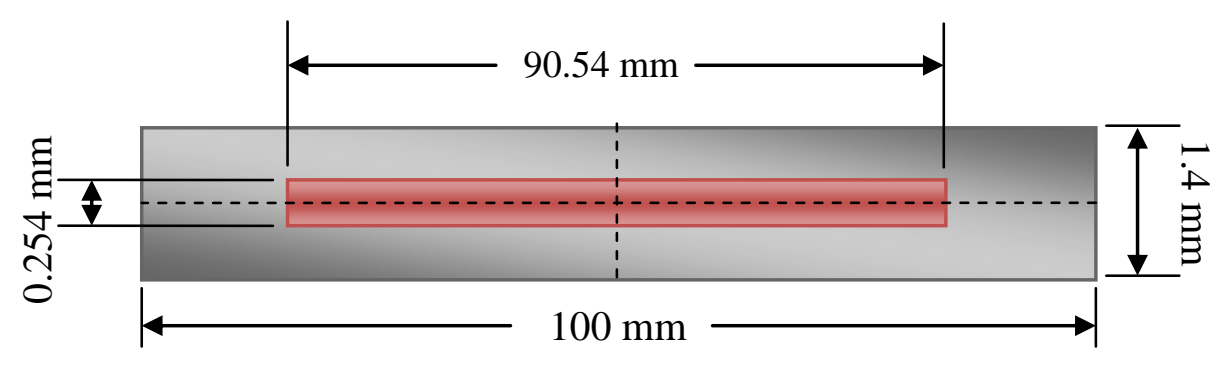

(case00) - Plate dimensions of nominal case

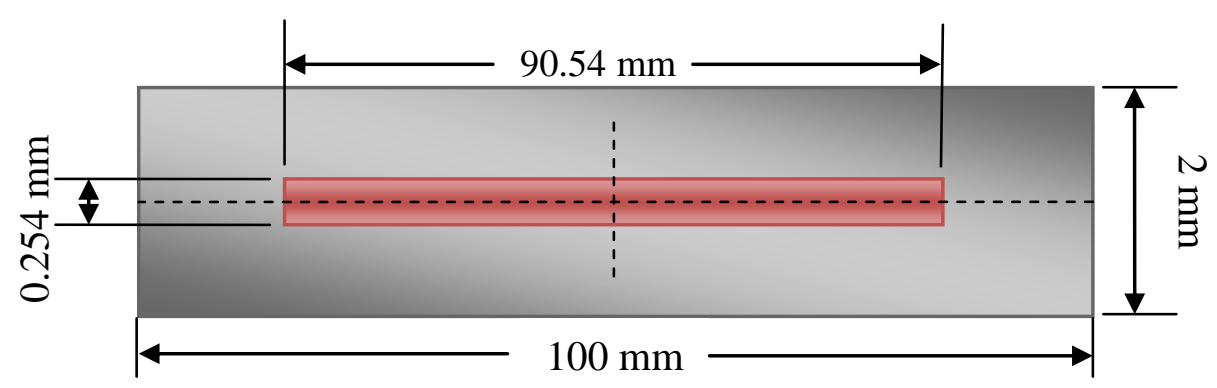

(case01) - Plate dimensions of with cladding thickness $=1.4$ times the nominal case 


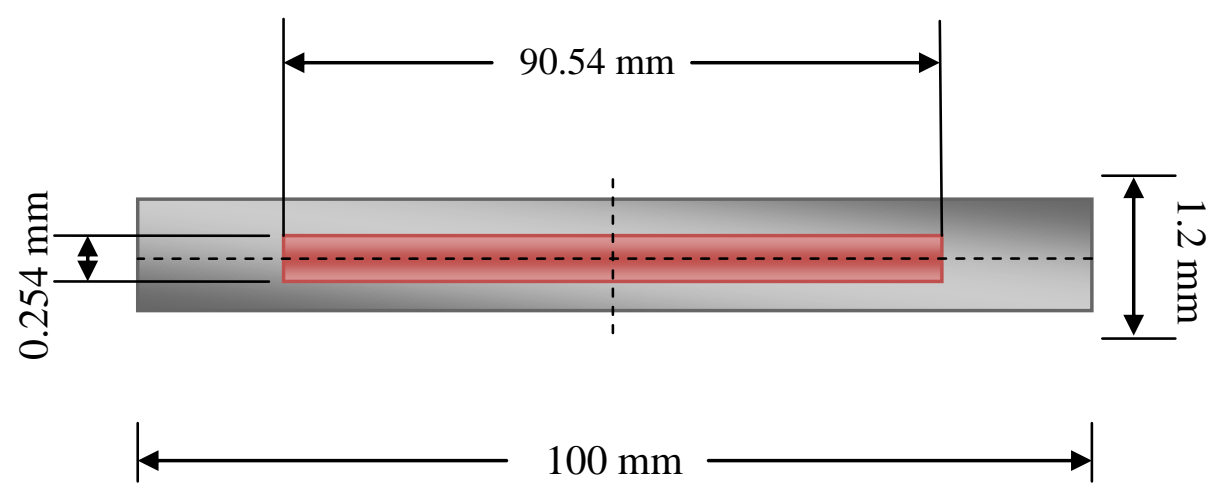

(case02) - Plate dimensions of with cladding thickness $=1.2$ times the nominal case

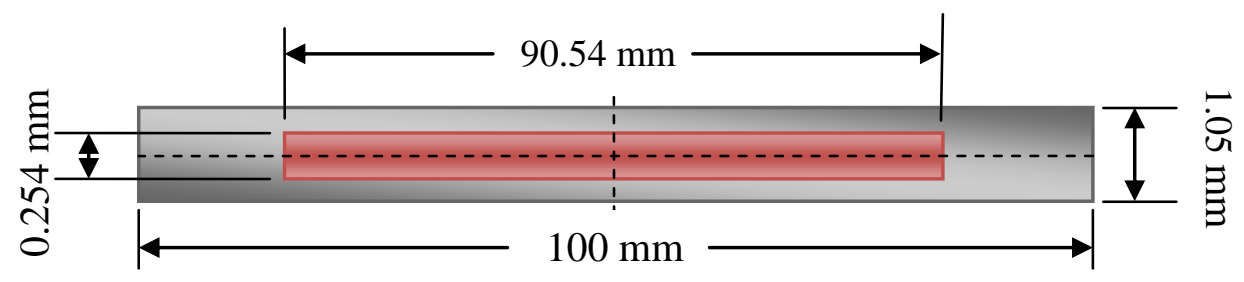

(case03) - Plate dimensions of with cladding thickness $=0.75$ times the nominal case

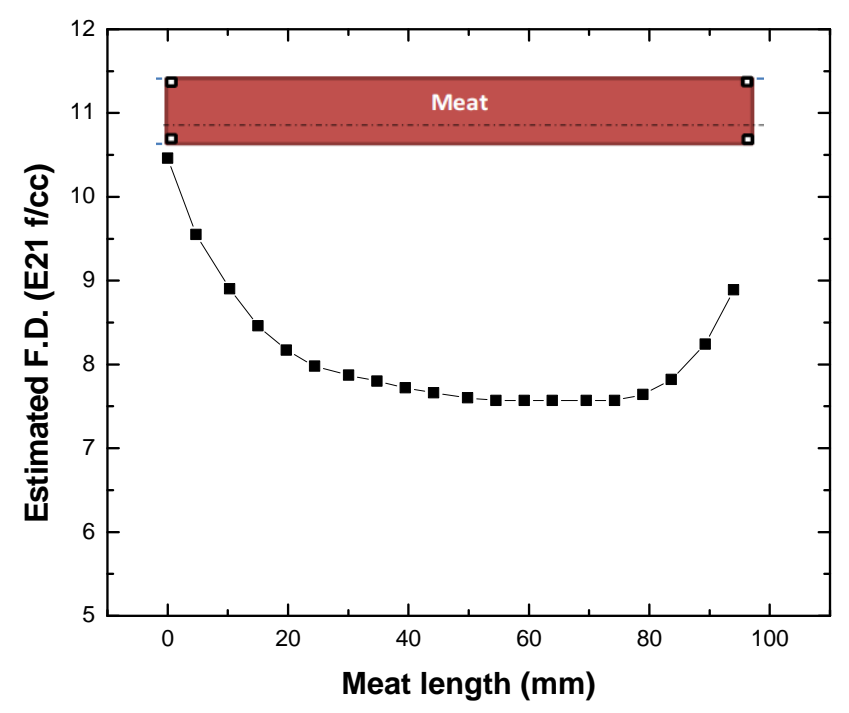

Spatial fission density distribution along the meat 


\section{Results and discussion}

The simulations were completed successfully in all cases and the coordinates of the top surface of the cladding were determined and the strain was estimated along that surface. The figure below shows the strain along the top cladding surface in all cases.

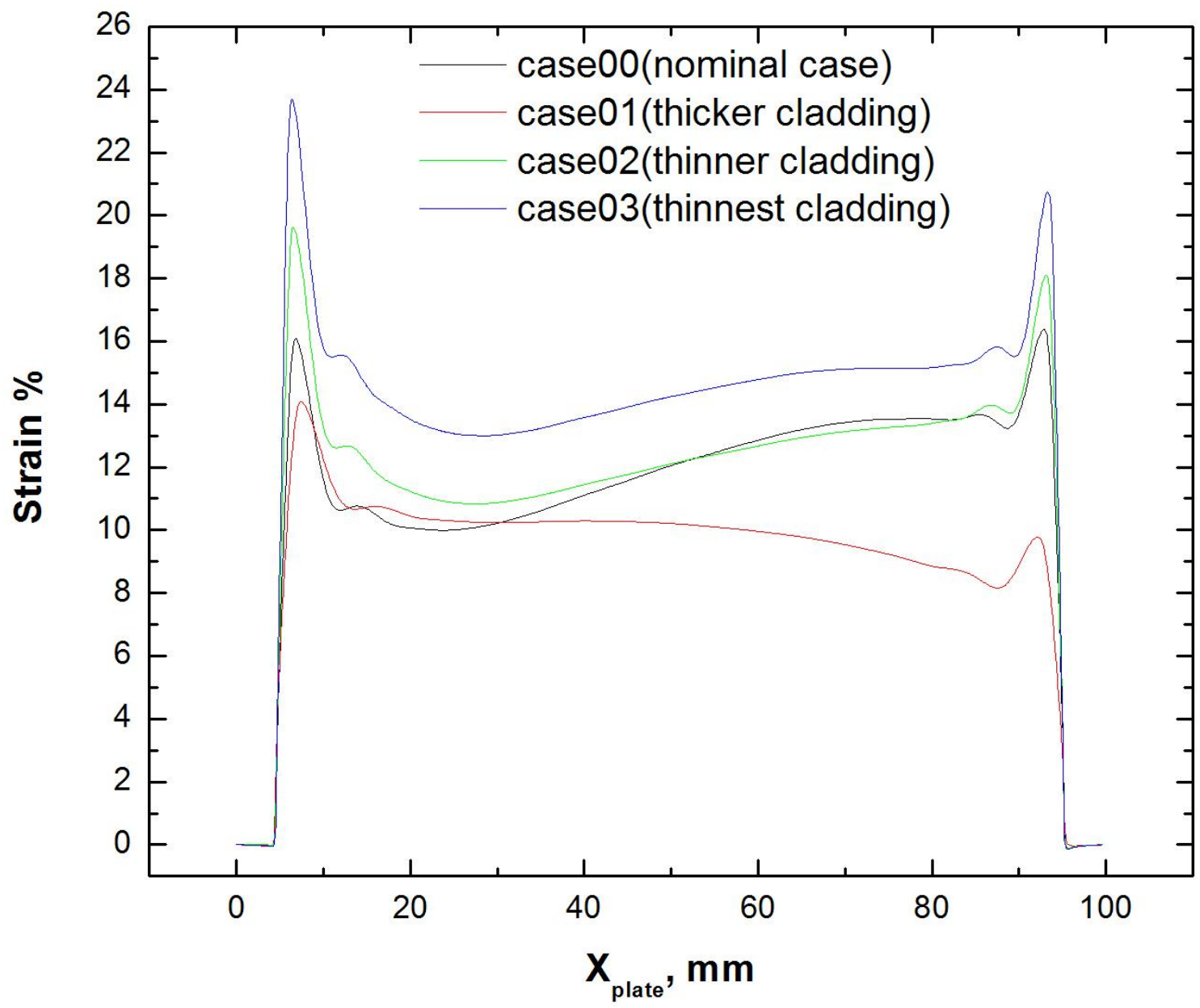

Figure 1 - Engineering strain along cladding top surface with different plate size 
As shown in figure 1, it is obvious that the peak cladding strain in all cases is observed in the vicinity of either of the maximum fission density locations (or both as in the nominal case). The following table lists the value of peak cladding strain and position at which it occurs in each case:

\begin{tabular}{|l|l|l|}
\hline Case & Peak cladding strain \% & X position $(\mathrm{mm})$ \\
\hline Case00 (nominal case) & $16.1,16.3$ & $6.75,93.08$ \\
\hline Case01 (thicker cladding) & 14.09 & 7.35 \\
\hline Case02 (thinner cladding) & 19.62 & 6.5 \\
\hline Case03 (thinnest cladding) & 23.71 & 6.39 \\
\hline
\end{tabular}

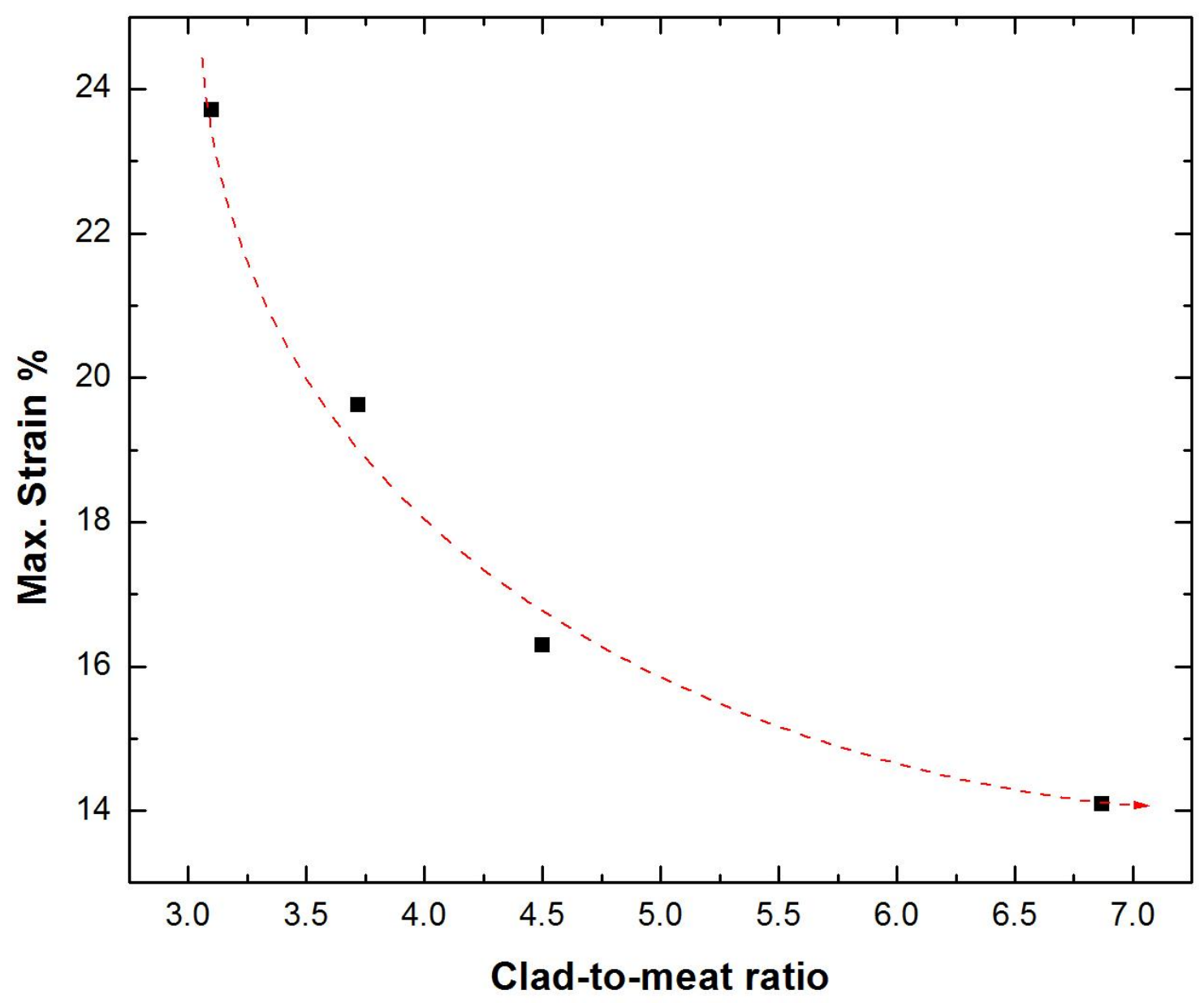

Figure 2 - Simulation results showing decrease in peak cladding strain as the cladding thickness increases 
According to figure 2 and the numerical values in the previous table, as the cladding-to-meat ration increases, the peak cladding strain decreases. This can be explained as the larger the cladding content of the plate allows the cladding to accommodate larger deformation. Furthermore, the change in plate size does not only influence the peak cladding strain but also has a visible effect on the cladding strain profile.

As the cladding content of the plate decreases, concentration of deformation seems to be more localized around the position of the peak of the fission density. Thus, the cladding-to-meat thickness ratio can be utilized as a parameter to control the influence of fission density on the cladding strain profile.

Thus, it is concluded that the peak cladding strain decreases as the cladding content of the plate increases. For certain spatial fission density along the meat section, the clad-to-meat ratio has a significant effect on the cladding strain profile. 


\section{Argonne}

Nuclear Engineering Division

Argonne National Laboratory

9700 South Cass Avenue, Bldg. 208

Argonne, IL 60439

www.anl.gov 